\title{
Quality of Life in Children With Epilepsy
}

\author{
Dimitrije M. Nikolić1,2, Željka Rogač3
}

\section{ABSTRACT}

Children with epilepsy are a particularly sensitive part of population and require continuous monitoring by neuro-paediatricians, so that any behavioural and functional changes that occur during mental maturation from the side effects of the therapy, but also the consequences of the disease itself, could be timely noticed. The aim of this paper is precisely to point out the potential difference in the quality of life of children with epilepsy, through the synthesis of relevant literature, in order to alert the local professional public about the need for mutual cooperation with neuro-paediatricians, psychologists, child psychiatrists, but also social workers and teachers at school.

Key words: children, epilepsy, quality of life.

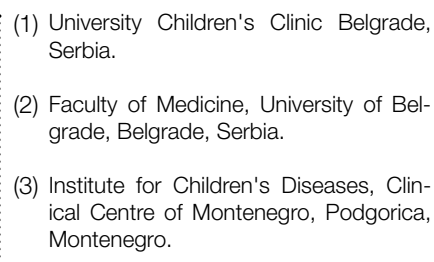

(3) Institute for Children's Diseases, Clinical Centre of Montenegro, Podgorica Montenegro.

Correspondence:

ŽELJKA ROGAČ

E: zeljka.rogac89@gmail.com

ARTICLE INFO

Received: 12 September 2019

Revision received: 25 September 2019 Accepted: 27 September 2019

\section{INTRODUCTION}

Contemporary epileptology is focused on shaping the definitions and classifications of epilepsy, inter alia with the aim of reducing a persistent stigma in the society around it, especially in developing countries. Epilepsy is nowadays no longer treated as a disorder, but as a disease. The latest classification, which has simplified the aetiological and clinical division of epileptic seizures, has enabled people with epilepsy and their immediate environment to better understand the diagnosis. ${ }^{1,2}$

Namely, it is known that the stigma used to be related to the fear of the unpredictable and unknown, because that is how epileptic seizures once seemed. Being a chronic disease that requires the use of antiepileptic therapy over a long period of time, epilepsy can greatly change the life of the patient and his/her family. The obligation to take daily therapy itself makes a patient lead a different life than his/her environment. There are also numerous side effects of antiepileptic drugs that lead to changes in physical appearance, behaviour, psychosocial and emotional functioning. On the other hand, weaker control of the incidence of epileptic sei- zures, limitations in playing sports, choosing a profession, may contribute to the impression of less value for those with the disease. All this can lead to anxiety and depression. ${ }^{3,4}$

Do children with epilepsy have a different lifestyle? Since epilepsy is a chronic disease with a sometimes diverse symptomatology of the onset of seizures, coping with the diagnosis varies from one diseased to another. Potential reactions to the disease are: a regression or withdrawal reaction that manifests as a form of helplessness; depressive reaction when the patients are inactive, unmotivated, unwilling and passively expecting help, projective reaction, when they are angry and wondering why they are sick of all people, when they often blame others for their own condition; a negative reaction, when patients do not perceive the seriousness of their status, do not see a reason for fear, do not cooperate with the doctor, and thus escape from reality; an adaptation or acceptance reaction when the sick invest a large amount of energy to cope with their illness. ${ }^{4,5}$

Since epilepsy can affect different spheres of 
life, questionnaires dealing with measuring the quality of life of patients, with little difference depending on the geographic area of validation, focus on the field of emotions, perception of reality, cognition, opportunities to perform daily physical activities, participate in social activities, social functioning of children and their parents. These studies are often associated with assessments of intellectual functioning, depression and suicide anxiety scales, estimates of compliance in terms of adherence to therapy, and control of seizure frequency. ${ }^{6,7}$

There are significant studies that have compared the lifestyles of patients with epilepsy and healthy children but also of those with other chronic diseases. In a study done in India, epilepsy patients were found to have a lower quality of life than those with migraine and diabetes mellitus, and to cope with greater stigma in the society than patients with other chronic diseases. They are also less likely to engage in sport activities, have fewer hobbies, and are more obese than the healthy controls. ${ }^{8}$

In a prospective 2-year follow-up study, epilepsy was found to be associated with impaired intellectual functioning, clearly indicating that at the start of the IQ trial both control and epilepsy groups were in the same bands. What was expected was a slight delay in intellectual functioning to be found in pharmacoresistant epilepsies, with a higher frequency of seizures. ${ }^{9}$

A study conducted in Western Europe found that a lower quality of life in children with epilepsy was associated with a lower educational level of parents. What is unusual about the results of that study is that more frequent visits to neuro-paediatricians are associated with greater anxiety and depression in children, as well as with poor school grades. ${ }^{10}$

Furthermore, Taylor et al. found that children with epilepsy are less likely to initiate social contacts, they feel frustrated about going to school trips and outings, start consuming cigarettes earlier and, although at a small higher percentage, are more prone to risky behaviour. ${ }^{11}$

Hamama-Raz et al. showed in their study that children with epilepsy sometimes had behavioural and concentration problems. This is a reason why research that seeks to compare the quality of life of patients with epilepsy and the side effects of antiepileptic therapy is interesting, as it often remains unclear what is the cause and what is the consequence. ${ }^{12}$

Many studies have sought to link psychic changes in children with epilepsy, and the type and frequency of seizures. The results are similar anxiety-depressive disorders and concentration problems are more prevalent in uncontrolled generalised tonic-clonic and partial onset seizures and what remains unknown is the cause and the effect between poorer quality of life and less active lifestyles. ${ }^{13,14}$

Children with epilepsy may have significantly more trauma and post-traumatic stress disorder than healthy controls and are well known to have more psychiatric illness than healthy controls. They cope with anxiety, depression and repressed feelings, and all this also can lead to the development of psychogenic non-epiletic seizures. ${ }^{15}$

Epilepsy may have a big role in choosing a profession, in family planning and also in various life organisation situations. If children with epilepsy do not receive adequate support from the family and the society, they may feel insecure about their life decision-making. ${ }^{16}$

Surveys of children the day after experiencing seizures at school or in the society show how much stigma, shame, fear of recurrence, and feelings of rejection children with epilepsy may sometimes cope with. ${ }^{12}$

Some studies that place the quality of life of children with epilepsy in the context of their growing environment have come to the conclusion that their families are similar to most families affected by a stressful life situation that necessarily leads to changes in family relationships and therefore and that there is an imperative that family relationships are balanced and imbued with emotions. ${ }^{13}$

Most studies, on the other hand, have come to the conclusion that if children have adequate support from the society, there are no limits to their daily functioning, nor is there a difference between the quality of life compared to healthy children and teenagers. ${ }^{9-14}$ 
How to improve the quality of life in children with epilepsy?

Recognition of the weak links in the relationship of children with epilepsy and their families indicates a need to insist on a multidisciplinary approach and on the involvement of psychologists, social support, educators of school staff in addition to neuro-paediatricians. Along with the efforts of pharmaceutical companies to find the most ideal antiepileptic drug, it is clear that a sick child needs to regain self-esteem and selflove, which is something that actually truly lies within the power of us, physicians. ${ }^{17}$

In more developed countries there are special programmes known as "Self-management for people with poorly controlled epilepsy". The goal of these programmes is to maximise the potential that children carry, despite suffering from epilepsy. As part of the program, psychologists trained in epilepsy and the potential side effects of antiepileptic therapy are hired. In addition to them, there are social workers in the school, who provide occasional education for school staff and healthy children about epilepsy, thus reducing social stigma and supporting the family of children with epilepsy. Also, the existence of the Association of Epilepsy Patients makes it possible that patients and their families, who often encounter similar obstacles, can support one another, and exchange experiences about therapy, overcoming difficulties in school and society.17, 18 Unfortunately, there are still no such programmes in our region, but it follows from all this that the whole team, led by a neuro-paediatrician, must encourage children with epilepsy to live life without restriction.

According to numerous studies, physical activity can significantly reduce the anxiety and depression in children with epilepsy. Practicing physical activity for children with epilepsy brings numerous benefits, has the effect of reducing anxiety and depression and enhances quality of life. ${ }^{17}$

Contemporary epileptology, when it comes to counselling a child with sports-related epilepsy, adheres to the guidelines issued in 2016 by the International League Against Epilepsy (ILAE). Different types of sports are divided into three groups, based on the dangers that the patient and his/her teammates may cause if the attack occurs during physical activity. After a patient is classified into one of the groups, one considers the type of epilepsy, characteristics and frequency of seizures, depending on the sport the patient wants to practice. Although the guidelines are clear, it is necessary to encourage the patient to practice appropriate sports activities if there is no danger to his or her health and the environment. ${ }^{18}$

In addition to monitoring seizures, correcting antiepileptic therapy, and reading EEG in the outpatient clinics of the neuro-paediatrician, attention must also be paid to the psychological status of the child and his/her family. Therefore, it is recommended that in the area of professional relationships inquire about their functioning as a family, to work together to find the best solution if there are problems. ${ }^{19,20,21}$

Due to the potential side effects of antiepileptic therapy, the implementation of standardised scales relating to anxiety and depression, suicidality, cognition, behavioural changes, quality of life of the diseased children and their parents, are recommended at the beginning of the introduction of therapy and after a year. In this way, chances to miss changes that the family may not be able to verbalise or reluctantly talk about are reduced. ${ }^{18,22}$

\section{CONCLUSION}

Children with epilepsy, based on relevant research on this topic, in most cases, have a lower quality of life because, in addition to the unpredictability of seizures, they struggle with anxiety, depression, and lower sense of self-esteem. Therefore, increased caution is needed for neuro-paediatricians, along with psychological monitoring and education of the environment and society to reduce the stigma that is still associated with epilepsy. All of these proposed recommendations are intended to completely monitor the patient with epilepsy during the paediatric period in order not to miss events that may lead to a decrease in quality of life. Except for being diagnosed with epilepsy, these children are no different from other children and can grow into individuals, with equal support from their healthy peers, who work, produce, and contribute to the society, as well as their healthy peers. 


\section{ACKNOWLEDGEMENTS}

None.

\section{REFERENCES}

1. Fisher RS, Acevedo C, Arzimanoglou A, Bogacz A, Cross JH, Elger CE, et al. ILAE Official Report: a practical clinical definition of epilepsy. Epilepsia 2014;55(4):475-82.

2. Falco-Walter JJ, Scheffer IE, Fisher RS. The new definition and classification of seizures and epilepsy. Epilepsy Res 2018;139:73-9.

3. Tejada J, Costa KM, Bertti P, Garcia-Cairasco N. The epilepsies: complex challenges needing complex solutions. Epilepsy Behav 2013;26(3):212-28.

4. Egunsola O, Choonara I, Sammons HM, Whitehouse WP. Safety of antiepileptic drugs in children and young people: a prospective cohort study. Seizure 2018;56:20-5.

5. Aguirre C, Quintas S, Ruiz-Tornero AM, Alemán G, Gago-Veiga AB, de Toledo M, et al. Do people with epilepsy have a different lifestyle. Epilepsy Behav 2017;74:27-32.

6. Elliott JO, Jacobson MP, Seals BF. Self-efficacy, knowledge, health beliefs, quality of life, and stigma in relation to osteoprotective behaviors in epilepsy. Epilepsy Behav 2006;9(3):478-91.

7. Arida RM, Cavalheiro EA, Scorza FA. From depressive symptoms to depression in people with epilepsy: contribution of physical exercise to improve this picture. Epilepsy Res 2012;99(1-2):1-13.

8. Jayashree N, Jain A, Dwivedi R. Quality of life in children with epilepsy. Ann Indian Acid Neurol. 2011;14(4):279-82.

9. Soria C, Sabbagh SE, Escolano S, Bobet R, Bulteau C, Dellatolas G. Quality of life in children with epilepsy and cognitive impairment: a review and a pilot study. Dev Neurorehabil 2007;10(3):213-21.

10. Fong CY, Chang WM, Kong AN, Rithauddin AM, Khoo TB, Ong LC. Quality of life in Malaysian children with epilepsy. Epilepsy Behav 2018;80:15-20.

11. Taylor J, Jacoby A, Baker GA, Marson AG. Self-reported and parent-reported quality of life of children and adolescents with new-onset epilepsy. Epilepsia 2011;52(8):1489-98.

12. Hamama-Raz Y, Hamama L. Quality of life among parents of children with epilepsy: a preliminary research study. Epilepsy Behav 2015;45:271-6.

\section{CONFLICT OF INTEREST}

None.
13. Mendes TP, Crespo CA, Austin JK. Family cohesion, stigma, and quality of life in dyads of children with epilepsy and their parents. J Pediatr Psychol 2017;42(6):689-99.

14. Puka K, Tavares TP, Anderson KK, Ferro MA, Speechley KN. A systematic review of quality of life in parents of children with epilepsy. Epilepsy and Behavior 2018;82:38-45.

15. Kapplan MJ, Dwivedi AK, Privitera MD, Isaacs K, Hughes C, Bowman M. Comparisons of childhood trauma, alexithymia, and defensive styles in patients with psychogenic non-epileptic seizures vs. epilepsy: implications for the etiology of conversion disorder. J Psychosom Res 2013;75(2):142-6.

16. Kunić S, Ibrahimagić OĆ, Vujković Z, Đajić V, Smajlović Dž, Mirković-Hajdukov M, et al. Emotional profile and employment of patients with epilepsy. Neuoquantology 2018;16(12):62-6.

17. Fitzsimons M, Normand C, Varley J, Delanty N. Evidence-based models of care for people with epilepsy. Epilepsy Behav 2012;23(1):1-6.

18. Capovilla G, Kaufman KR, Perucca E, Moshé SL, Arida RM. Epilepsy, seizures, physical exercise, and sports: a report from the ILAE Task Force on Sports and Epilepsy. Epilepsia 2015;57(1):6-12.

19. Dash D, Sebastian TM, Aggarwal M, Tripathi M. Impact of health education on drug adherence and selfcare in people with epilepsy with low education. Epilepsy Behav 2015;44:213-7.

20. Aliasgharpour M, Dehgahn NN, Yadegary MA, Haghani H. Effects of an educational program on self-management in patients with epilepsy. Seizure 2013;22(1):48-52.

21. Laybourne AH, Morgan M, Watkins SH, Lawton R, Ridsdale L, Goldstein LH. Self-management for people with poorly controlled epilepsy: participants' views of the UK Self-Management in epILEpsy (SMILE) program. Epilepsy Behav 2015;52:159-64.

22. Noam Y, Raol YH, Holmes GL. Searching for new targets for treatment of pediatric epilepsy. Epilepsy Behav 2013;26(3):253-60. 